\title{
NLRP3 inflammasome activation contributes to remifentanil-induced postoperative hyperalgesia via regulation of NMDA receptor NR1 subunit phosphorylation and GLT-1
}

\author{
Yuan Yuan ( $\nabla$ js9vu8@163.com ) \\ Chenxu Wang \\ Tianjin Medical University General Hospital \\ Beibei Dong \\ Tianjin Medical University General Hospital \\ Keliang Xie \\ Tianjin Medical University General Hospital \\ Yonghao Yu \\ Tianjin Medical University General Hospital
}

Tianjin Medical University General Hospital https://orcid.org/0000-0002-3338-3189

\section{Research article}

Keywords: HDAC3, circadian clock gene oscillations, mitophagy, myocardial ischemia/reperfusion injury

Posted Date: April 22nd, 2020

DOI: https://doi.org/10.21203/rs.3.rs-23650/v1

License: (c) (i) This work is licensed under a Creative Commons Attribution 4.0 International License.

Read Full License 


\section{Abstract}

\section{Background}

Although remifentanil provides perfect analgesia during operations, postoperative remifentanil-induced hyperalgesia (RIH) might be a challenge to anaesthetists. Increasingly, the NOD-like receptor protein 3 (NLRP3) signalling pathway are being implicated in the initiation and maintenance of these conditions. In the present work, we examined the hypothesis that NLRP3 inflammasome activation contributes to RIH via regulation of NMDA receptor NR1 subunit phosphorylation and glutamate transporter-1 (GLT-1) by interleukin-1 $\beta$ (IL-1 $\beta)$.

Methods

We first tested the changes in thermal and mechanical hyperalgesia at baseline ( $24 \mathrm{~h}$ before remifentanil infusion) and $2 \mathrm{~h}, 6 \mathrm{~h}, 24 \mathrm{~h}$, and $48 \mathrm{~h}$ after remifentanil infusion in a rat model of incisional pain. Then, the expression of IL-1 $\beta$ and GLT-1 and phosphorylation of NMDA receptor NR1 subunits (Phospho-NR1) in the L4-L6 spinal cord segments were measured. Furthermore, we investigated the effects of IL-1 ra, a selective IL-1 $\beta$ inhibitor, on behavioural tests of RIH and on the expression of GLT-1 and Phospho-NR1. In addition, we measured the expression of TLR4, P2X7R, NLRP3 and caspase-1, which are indicators of NLRP3 inflammasome activation. Finally, we investigated the effects of (+)-naloxone (a TLR4 inhibitor), A438079 (a P2X7R inhibitor) and ac-YVADcmk (a caspase-1 inhibitor), which are all selective NLRP3 inflammasome inhibitors, on behavioural tests of RIH and on the expression of IL-1 $\beta$, GLT-1 and PhosphoNR1.

\section{Results}

The initiation and maintenance of RIH was mediated by a previously unidentified mechanism-namely, remifentanil-induced spinal NLRP3 inflammasome activation and the associated release of IL-1 $\beta$. Remifentanil induced significant postoperative hyperalgesia, as indicated by behavioural tests, which were markedly improved by pretreatment with IL-1 ra and NLRP3 inflammasome inhibitors. Moreover, remifentanil infusion decreased the expression of GLT-1 and increased Phospho-NR1 in the spinal cord, which were reversed by pretreatment with IL-1ra and NLRP3 inflammasome inhibitors. More importantly, remifentanil infusion increased IL-1 $\beta$ expression and activated NLRP3 inflammasomes, which were significantly attenuated by NLRP3 inflammasome inhibitors.

\section{Conclusion}

The above results suggest that NLRP3 inflammasome activation contributes to RIH via regulation of Phospho-NR1 and GLT-1 by IL-1 $\beta$. Inhibition of NLRP3 inflammasome activation or IL-1 $\beta$ may be an effective and novel option for the treatment of RIH.

\section{Background}


Opioids are the drugs of the essence for anaesthesia in clinic. However, the onset of opioid-induced hyperalgesia $(\mathrm{OIH})$ has been demonstrated to be associated with the use of opioids. OlH is defined as increased pain from noxious stimuli[1, 2]. Remifentanil is an ultra short-acting opioid which is often used as an analgesic for general anaesthesia and other medical fields. A large number of research have confirmed that intraoperative use of remifentanil may increase postoperative pain scores and the need for opioids [3-5] despite these popular characteristics. Numerous studies focusing on RIH have been published. However, the mechanisms underlying RIH are not clear.

We predicted that incisions triggered the release of danger-associated molecular patterns (DAMPs) and DAMPs initiate Toll-like receptor 4 (TLR4) signalling pathway. TLR4 signalling pathway is also activated by remifentanil. In addition, the combination of incisions and remifentanil treatment may activate a unique mechanism in opioid treatment-in other words, activation of the NLRP3 inflammasome, which is a protein complex. The activation of the NLRP3 inflammasome then activates IL-1 $\beta$, which is a gatekeeper of inflammation[6, 7]. TLR4 signalling pathway increases the expression of NLRP3 and pro-IL$1 \beta[8]$, which contributes to the activation of the NLRP3 inflammasome. The role of TLR4 in OIH and hyperalgesic priming has been proven[9]. The purinergic receptor $\mathrm{P} 2 \times 7 \mathrm{R}$ is the second signal which leads to the association of NLRP3, the adaptor protein apoptosis-associated speck-like protein containing a CARD (ASC), and caspase-1. In the end the activation of the NLRP3 inflammasome allowed the proteolytic activation of IL-1 $\beta[10]$.

IL-1 $\beta$ may excite secondary nociceptive neurons by several proved mechanisms. One of the mechanisms is the phosphorylation of postsynaptic NR1 NMDA receptor subunits[11], the other one is the downregulation of GLT-1[12].

NMDA receptors are ionotropic glutamate receptors which contrubutes to excitatory synaptic transmission. NMDA NR1 subunit, NR2 subunit and NR3 subunit are the three kinds of NMDA receptor subunits. The trafficking and activation of NMDA receptor NR1 subunits have a pivotal role in the development and maintenance of RIH[13]. The trafficking of NMDA receptor NR1 subunits depends on the phosphorylation of NMDA receptor NR1 subunits[14].

GLT-1 is primarily responsible for glutamate clearance in the spinal cord. Repeated opioid administration reduces spinal GLT-1 expression. Glutamate is the primary excitatory neurotransmitter in the central nervous system that initiates rapid signal transmission in the synapse before its re-uptake into the surrounding glia, specifically, astrocytes. GLT-1 is the major transporter that takes up synaptic glutamate to maintain optimal extracellular glutamic levels, thus preventing accumulation in the synaptic cleft and consequent excitotoxicity. Growing evidence has shown that excitotoxicity is associated with various neurological disorders, including $\mathrm{OIH}[15]$. While the mechanisms of $\mathrm{RIH}$ are not well understood, the down-regulation of GLT-1 may play a significant role in RIH.

The aim of the present study was to test whether RIH is mediated by spinal NLRP3 inflammasome activation. We hypothesized that NLRP3 inflammasome activation contributes to RIH via regulation of Phospho-NR1 and GLT-1 by IL-1 $\beta$. Inhibition of either NLRP3 inflammasome activation or IL-1 $\beta$ may be an 
effective and novel option for the treatment of RIH. This study might provide new insights into the mechanism and protection of RIH.

The design concept of our study is summarized in Fig. 1.

In clinical practice, patients always accept anesthesia and operation simultaneously. So Incision + Remifentanil group was designed to imitate RIH in clinical practice. We used a rat model of postoperative pain. SD rats were selected because they are the most commonly used animals for studied about RIH.

\section{Methods}

\section{Animals}

In all experiments we used Adult male Sprague-Dawley rats (240-260 g, provided by the Laboratory Animal Center of the Military Medical Science Academy of the PLA ). The animals were fed confirming to the protocols approved by the Institutional Animal Care and Use Committee of Tianjin Medical University. All experimental operations were approved by the committee of experimental animals of Tianjin Medical University.

\section{Drugs}

Remifentanil hydrochloride purchased from RenFu Co. (Guangzhou, China) was dissolved in saline (NaCl $0.9 \%$ ) and infused intravenously at a rate of $1.2 \mu \mathrm{g} \cdot \mathrm{kg}^{-1} \cdot \mathrm{min}^{-1}$ for $60 \mathrm{~min}$, based on a previously reported dose[16]. Controls received the same volume of saline under identical conditions. Sevoflurane was purchased from Maruishi Pharmaceutical Co. (Osaka, Japan). IL-1ra was purchased from Abcam (Cambridge, England). A438079 was purchased from Tocris Bioscience (Bristol, England). Sterile saline was the vehicle for all drugs, except acYVAD-cmk [3\% (vol/vol) DMSO]. (+)-Naloxone, ac-YVAD-cmk and DMSO were purchased from Sigma Aldrich (St. Louis, MO, USA). For intrathecal drug delivery, the catheters were preloaded with drugs at the distal end in a total volume and delivered over 20-30 s once the catheter was in position. Intrathecal doses were as follows: IL-1ra: $100 \mu \mathrm{g}$ in $10 \mu \mathrm{L} ;(+)$-naloxone: $1200 \mu \mathrm{g}$ in $10 \mu \mathrm{L}$; A438079: $600 \mathrm{ng}$ in $10 \mu \mathrm{L}$; and ac-YVADcmk: $20 \mu \mathrm{g}$ in $10 \mu \mathrm{L}$, based on a previously reported dose[17]. Respective equivolume vehicles were used as controls.

\section{Intrathecal Catheter Implantation}

The intrathecal catheter implantation was on the basis of previously described methods $[17,18]$. Briefly, an intrathecal polyethylene (PE-10) catheter was inserted into the subarachnoid space at the level of the spinal cord lumbar enlargement segments through an incision at the atlanto-occipital membrane. After a 1-week recovery, rats that showed any neurologic impairment according to locomotor function testing were discarded.

\section{Anesthesia And Surgical Procedure}


Animals were anesthetized with sevoflurane (induction, 3.0\% v/v; surgery, $1.0 \% \mathrm{v} / \mathrm{v}$ ) via a nose mask. We used the postoperative pain model described by Brennan et a凡19]. We made a 1-cm longitudinal incision with a number 11 blade through the skin and fascia of the plantar aspect of the left hind paw. The incision started $0.5 \mathrm{~cm}$ from the proximal edge of the heel and extended towards the toes. Then, we elevated the plantaris muscle and incised longitudinally. The muscle origin and insertion remained intact. After haemostasis was achieved, we closed the skin with two 4 - 0 silk sutures. We covered the wound with erythromycin ointment for prevention of infection.

\section{Experimental Protocol}

Experiment One: The changes in mechanical and thermal hyperalgesia, IL-1 $\beta$ expression, GLT-1, PhosphoNR1 and the indicators of NLRP3 inflammasome activation in RIH (TLR4, P2 $\times 7 R$, NLRP3 and caspase1).

The animals were randomly divided into 4 groups $(n=8)$ based on a randomization list provided by the Department of Anaesthesiology, Tianjin Medical University General Hospital according to relevant Standard Operating Procedure(computer-generated random number system): Sham + NS group: animals underwent a sham operation with NS infusion; Sham + Remifentanil group: animals underwent a sham operation with a remifentanil infusion; Incision + NS group: animals underwent a surgical incision with an NS infusion; and Incision + Remifentanil group: animals underwent a surgical incision with a remifentanil infusion. Remifentanil hydrochloride was dissolved in saline $(\mathrm{NaCl} 0.9 \%)$ and infused intravenously at a rate of $1.2 \mu \mathrm{g} \cdot \mathrm{kg}^{-1} \cdot \mathrm{min}^{-1}$ for $60 \mathrm{~min}$. The animals in the Sham + NS and Incision + NS groups received the same volume of saline under identical conditions. The withdrawal threshold and withdrawal latency to mechanical and thermal stimulation, respectively, were evaluated at baseline ( $24 \mathrm{~h}$ before remifentanil infusion) and $2 \mathrm{~h}, 6 \mathrm{~h}, 24 \mathrm{~h}$ and $48 \mathrm{~h}$ after remifentanil infusion. The L4-L6 segments of the spinal cord were collected after the last behavioural test to measure the expression of IL-1 $\beta$ as well as GLT-1, Phospho-NR1 and the indicators of NLRP3 inflammasome activation (TLR4, P2 × 7R, NLRP3 and caspase-1).

Experiment Two: The effects of an IL-1 $1 \beta$ inhibitor, IL-1 ra, on mechanical and thermal hyperalgesia, GLT-1, and Phospho-NR1 in RIH.

The animals were randomly divided into 3 groups $(n=8)$ : Sham + NS + vehicle group: animals underwent a sham operation with an NS and vehicle infusion; Incision + Remifentanil + vehicle group: animals underwent a surgical incision with a remifentanil and vehicle infusion; and Incision + Remifentanil + IL1ra: animals underwent a surgical incision with a remifentanil infusion and IL-1 ra. Remifentanil was administered as in the above experiment. IL-1ra $(100 \mu \mathrm{g}$ in $10 \mu \mathrm{L})$ was intrathecally administered immediately before remifentanil infusion. The animals in the Sham + Remifentanil + vehicle group and Incision + Remifentanil + vehicle group received the same volume of the vehicle under identical conditions. The withdrawal threshold and withdrawal latency to mechanical and thermal stimulation, respectively, were performed at baseline ( $24 \mathrm{~h}$ before remifentanil infusion) and $2 \mathrm{~h}, 6 \mathrm{~h}, 24 \mathrm{~h}$ and $48 \mathrm{~h}$ 
after remifentanil infusion. The L4-L6 segments of the spinal cord were collected after the last behavioural test to measure the levels of GLT-1 and Phospho-NR1.

Experiment Three: The effects of (+)-naloxone (a TLR4 inhibitor), A438079 (a P2 × 7R inhibitor) and acYVADcmk (a caspase-1 inhibitor) on mechanical and thermal hyperalgesia, IL-1ß, GLT-1, and PhosphoNR1 in RIH.

The animals were randomly divided into 5 groups $(n=8)$ : Sham + NS + vehicle group: animals underwent a sham operation with an NS and vehicle infusion; Incision + Remifentanil + vehicle group: animals underwent a surgical incision with remifentanil and vehicle infusion; Incision + Remifentanil+(+)-naloxone group: animals underwent a surgical incision with a remifentanil infusion and (+)-naloxone; Incision + Remifentanil + A438079 group: animals underwent a surgical incision with a remifentanil infusion and A438079; and Incision + Remifentanil + ac-YVAD-cmk group: animals underwent a surgical incision with a remifentanil infusion and ac-YVAD-cmk. Remifentanil was administered as in the above experiment. (+)Naloxone $(1200 \mu \mathrm{g}$ in $10 \mu \mathrm{L}), \mathrm{A} 438079$ (600 ng in $10 \mu \mathrm{L})$, and ac-YVAD-cmk (20 $\mu \mathrm{g}$ in $10 \mu \mathrm{L})$ were intrathecally administered immediately before remifentanil infusion. The animals in the Sham + NS + vehicle group and Incision + Remifentanil + vehicle group received the same volume of the vehicle under identical conditions. The withdrawal threshold and withdrawal latency to mechanical and thermal stimulation, respectively, were performed at baseline ( $24 \mathrm{~h}$ before remifentanil infusion) and $2 \mathrm{~h}, 6 \mathrm{~h}, 24 \mathrm{~h}$ and $48 \mathrm{~h}$ after remifentanil infusion. The L4-L6 segments of the spinal cord were collected after the last behavioural test to measure the levels of IL-1 $\beta$, GLT-1 and Phospho-NR1.

\section{Behavioural Tests}

\section{Mechanical Hyperalgesia}

We used an electronic Von Frey filament (BSEVF3, Harvard Apparatus, USA) to measure the paw withdrawal threshold (PWT). Animals were placed in wire chambers $(20 \mathrm{~cm} \times 20 \mathrm{~cm} \times 20 \mathrm{~cm})$ with a grid bottom. The animals were allowed to acclimatize for $1 \mathrm{~h}$ before testing. The filament was applied vertically to the area adjacent to the wound of the left hind paw with increasing pressure. the PWT was defined as the pressure ( $\mathrm{g}$ ) at which the rat flinched, shook, or licked its paw. The test was repeated three times at 5-minute intervals. The mean of the 3 trials was regarded as the PWT. We used a cut-off pressure of $60 \mathrm{~g}$ to avoid tissue damage.

\section{Thermal Hyperalgesia}

We used an intellective hot plate equipment (YLS-6B, Zheng Hua Biological Instrumentation Co., China) to measure the paw withdrawal latency (PWL). Animals were allowed to acclimatize to the environment for $1 \mathrm{~h}$ before testing. They were placed on a hot plate $\left(50^{\circ} \mathrm{C}\right)$. The PWL was defined as the time (s) when the rat appeared positive response (a clear paw withdrawal). The test was repeated three times at 10-minute intervals. The mean of the 3 trials was regarded as the PWL. We used a cut-off time of $30 \mathrm{~s}$ to avoid tissue damage. 


\section{Tissue Preparation}

We used the method of overdose anesthesia for euthanasia. Animals were anesthetized with pentobarbital $(130 \mathrm{mg} / \mathrm{kg})$ for intraperitoneal injection. The $L_{4-6}$ spinal cord was rapidly removed and frozen in liquid nitrogen.

\section{Quantification of mRNA via Real-time PCR}

The levels of IL-1 $\beta$ mRNA in the spinal cord were determined after the last behavioural test. The $L_{4-6}$ spinal cord was removed and frozen in liquid nitrogen. Total RNA was extracted with TRIzol (Invitrogen, Carlsbad, CA, USA). Then, total RNA was transcribed into cDNA with a cDNA Reverse Transcription Kit (Applied Biosystems, Foster City, CA, USA) according to the manufacturer's instructions. The expression of IL-1 $\beta$ mRNA was determined by real-time PCR using SYBR Green PCR Master Mix (Roche, Mannheim, Germany). Glyceraldehyde-3-phosphate dehydrogenase (GAPDH) was used as an internal control. Each test was run in triplicate. The primers of IL-1 $\beta$ and GAPDH were designed and synthesized by SBS Genetech Co., Ltd. (IL-1 $\beta$ Forward 5'-GAGGCTCCATCTCCAAGGAC-3', Reverse 3'-

ACTGTGTGTGACAGGTTGGA-5'; GAPDH Forward 5'-TGATGGGTGTGAACCACGAG-3', Reverse 3'ATCACGCCACAGCTTTCCAG-5'). IL-1 $\beta$ gene expression was calculated with the delta-delta-Ct method[20].

\section{Protein Analysis via Western Blot}

The tissues from the $L_{4-6}$ spinal cord were removed after the last behavioural test and frozen in liquid nitrogen. Tissues were homogenized in an SDS sample buffer containing proteinase inhibitors. The homogenate was centrifuged at $4{ }^{\circ} \mathrm{C}(12,000 \mathrm{rpm}, 10$ minutes $)$, and the he supernatant liquor was pipette as the total protein. The protein content was determined using the bicinchoninic acid (BCA) assay method. Before the proteins were transferred to PVDF membranes, they were separated on an SDS-PAGE gel. The membranes were blocked with $5 \%$ non-fat milk for $1 \mathrm{~h}$ on the shaker

and subsequently incubated with primary antibody rabbit anti-phospho-NR1 (1:500, ab75680, Abcam), rabbit anti-GLT-1 (1:1000, ab106289, Abcam), rabbit anti-TLR4 (1:1200, ab13867, Abcam), rabbit anti-P2 $\times$ 7R (1:1000, ab48871, Abcam), rabbit anti-NLRP3 (1:1000, ab214185, Abcam) and rabbit anti-caspase-1 antibodies (1:1000, ab62698, Abcam) overnight at $4{ }^{\circ} \mathrm{C}$. The membranes were washed with TBST buffer for 30 min and incubated with secondary antibody (goat anti-rabbit IgG, HRP, 1:5000, ab7090, Abcam) for $1 \mathrm{~h}$ at room temperature. The proteins were visualizedby enhanced

chemiluminescence detection (Millipore, Billerica, MA) using a Bio-Rad GS-700 imaging system with software (Bio-Rad, Hercules, CA,USA). $\beta$-Actin was used as a loading control. The results are expressed as the percentage of $\beta$-actin immunoreactivity.

\section{Enzyme-linked Immunosorbent Assay (ELISA)}

The level of IL-1 $\beta$ in the rat $\mathrm{L}_{4-6}$ ipsilateral dorsal spinal cord was detected by ELISA kits (Abcam) according to the attached instructions of the kits. 


\section{Statistical Analysis}

GraphPad Prism 5 was used to generate the graphics and perform statistical analyses. All data were expressed as the mean \pm standard deviation (SD). In nociceptive behavioural tests, a repeated measures analysis of variance (ANOVA) was performed to determine the overall differences in the PWT and PWL at each time point. To analyze the results of real-time PCR, western blot and ELISA, a one-way ANOVA was used. A P value less than 0.05 was considered statistically significant.

\section{Results}

\section{Remifentanil amplifies postoperative hyperalgesia - Changes in behavioural tests}

To assess whether remifentanil could induce hyperalgesia, remifentanil $\left(1.2 \mu \mathrm{g} \cdot \mathrm{kg}^{-1} \cdot \mathrm{min}^{-1}\right)$ or saline was intravenously infused in the absence or presence of a left hind paw incision for $60 \mathrm{~min}$. The PWT to von Frey filament stimulation and PWL to thermal stimulation were evaluated at $24 \mathrm{~h}$ before the incision and $2 \mathrm{~h}, 6 \mathrm{~h}, 24 \mathrm{~h}$, and $48 \mathrm{~h}$ after remifentanil infusion. Compared with baseline, the control animals (animals in the Sham + NS group) did not show significant changes in the PWT or PWL ( $P>0.05$, Fig. 2). Compared with baseline and the Sham + NS group, both a plantar incision (Incision + NS group) and remifentanil infusion (Sham + Remifentanil group) induced a significant decrease in the PWT and PWL in the left paw during the postoperative period from $2 \mathrm{~h}$ to $48 \mathrm{~h}(\mathrm{P}<0.01$, Fig. 2). Furthermore, intraoperative infusion of remifentanil significantly enhanced mechanical and thermal hyperalgesia induced by the incision, which was manifested by a significant decrease in the PWT and PWL $(P<0.01$, Incision + Remifentanil group vs Incision + NS group, Fig. 2). These results demonstrate that we successfully established a rat model of remifentanil-induced postoperative hyperalgesia and that remifentanil amplifies postoperative hyperalgesia.

\section{Remifentanil enhanced proinflammatory cytokine IL-1 $\beta$ signalling-Changes in IL-1 $\beta$ mRNA and protein, Phospho- NR1 and GLT-1 protein}

There was a significant increase in IL-1 $\beta$ mRNA and protein in the spinal cord of animals in the groups that underwent remifentanil administration (Sham + Remifentanil), surgical incision (Incision $+N S$ ) or both (Incision + Remifentanil) when compared with those of animals in the Sham + NS group $(P<0.01$, Fig. 3A, 3B). In addition, intraoperative infusion of remifentanil induced a significant increase in IL-1 $\beta$ mRNA and protein in the spinal cord of rats compared with surgical incision $(P<0.01$, Incision + Remifentanil group vs Incision + NS group, Fig. $3 \mathrm{~A}$ and $3 \mathrm{~B}$ ). This result suggests that both remifentanil and surgery can increase the expression of IL-1 $\beta$ mRNA and protein in the spinal cord and that incisioninduced IL-1 $\beta$ expression is enhanced by remifentanil. 
There are several known mechanisms by which IL-1 $\beta$ may increase the excitability of second-order nociceptive projection neurons, including phosphorylation of postsynaptic NR1 NMDA receptor subunits (35), and downregulation of GLT-1. The respective levels of these proteins were assessed. Phospho-NR1 was elevated, whereas GLT-1 decreased with the combination of an incision and remifentanil (Fig. 3C-F). These data provide biochemical validation of the amplified hyperalgesia presented in Fig. 2 and additional supportive evidence that RIH depended on IL-1 $\beta$ signalling.

\section{IL-1 $\beta$ mediates RIH-Effects of IL-1 $\beta$ inhibition on behavioural tests}

The IL-1 $\beta$ receptor antagonist IL-1ra was intrathecally administered to test whether spinal IL-1 $\beta$ mediated $\mathrm{RIH}$. Compared with the animals at baseline and animals in the Sham + NS + vehicle group, the animals in the Incision + Remifentanil + vehicle group developed mechanical and thermal hyperalgesia, which was reflected by a decrease in the PWT and PWL $(P<0.01$, Fig. 4) during the postoperative period and was significantly attenuated by pretreatment with IL-1ra (Fig. 4). This result demonstrates that IL-1 $\beta$ inhibition can partly prevent $\mathrm{RIH}$. These data indicate that the initiation and maintenance of RIH depended on IL-1 $\beta$.

\section{Effects of IL-1 $\beta$ inhibition on Phospho-NR1 and GLT-1 protein}

Compared with the Sham + NS + vehicle group, the Incision + Remifentanil + vehicle group experienced an increase in the levels of Phospho-NR1 and a decrease in GLT-1, which were significantly reversed by pretreatment with IL-1ra, an IL-1 $\beta$ inhibitor (Fig. 5). This result demonstrates that IL-1 $\beta$ inhibition can partly prevent RIH via regulation of Phospho-NR1 and GLT-1.

RIH is associated with NLRP3 inflammasome activation-Changes in the indicators of NLRP3 inflammasome activation (TLR4, P2 × 7R, NLRP3, and caspase-1)

There was a significant increase in TLR4, P2 $\times 7 R, N L R P 3$, and caspase- 1 protein in the spinal cord of animals in the groups that underwent remifentanil administration (Sham + Remifentanil), surgical incision (Incision + NS) and their combination (Incision + Remifentanil) when compared with the Sham + NS group $(P<0.01$, Fig. 6$)$. In addition, intraoperative infusion of remifentanil induced a significant increase in TLR4, P2 $\times 7 R$, NLRP3, and caspase-1 protein in the spinal cord of rats compared with surgical incision $(P<0.01$, Sham + Remifentanil group vs Incision + NS group, Fig. 6$)$. This result suggests that both remifentanil and surgery can increase the expression of TLR4, P2 $\times 7 R$, NLRP3, and caspase-1 protein in the spinal cord and that RIH is associated with NLRP3 inflammasome activation.

\section{NLRP3 inflammasome activation mediates RIH-Effects of NLRP3 inflammasome inhibition on behavioural tests}


Compared with animals at baseline and animals in the Sham + NS + vehicle group, animals in the Incision + Remifentanil + vehicle group developed mechanical and thermal hyperalgesia, which was reflected by decreases in the PWT and PWL $(P<0.01$, Fig. 7) during the postoperative period, which were significantly attenuated by pretreatment with (+)-naloxone, A438079, ac-YVAD-cmk, an inhibitor of TLR4, P2 $\times 7 R$, and caspase- 1 (Fig. 7). This result demonstrates that NLRP3 inflammasome inhibition can partly prevent RIH.

\section{Effects of NLRP3 inflammasome inhibition on IL-1 $\beta$, GLT-1 and Phospho-NR1}

Compared with the levels in the Sham + NS + vehicle group, the levels of IL-1 $\beta$ and Phospho-NR1 were elevated in the Incision + Remifentanil + vehicle group, whereas GLT-1 decreased, which were significantly reversed by pretreatment with (+)-naloxone, A438079, ac-YVAD-cmk, an inhibitor of TLR4, P2 $\times 7 R$, and caspase-1 (Fig. 8). This result demonstrates that NLRP3 inflammasome inhibition can partly prevent RIH via regulation of the levels of IL-1 $\beta$, Phospho-NR1 and GLT-1.

\section{Discussion}

Our results showed that intraoperative infusion of remifentanil down-regulated the nociceptive thresholds (PWT and PWL) at different time points during the postoperative period. Moreover, intraoperative infusion of remifentanil increased the expression of TLR4, P2 $\times 7 R$, NLRP3, and caspase- 1 , which are indicators of NLRP3 inflammasome activation, and the expression of IL-1 $\beta$ mRNA and protein, which are the downstream products of NLRP3 inflammasome activation. In addition, the present study showed that remifentanil infusion induced increased Phospho-NR1 and decreased GLT-1 protein, which were reversed by pretreatment with IL-1 ra, a selective inhibitor of IL-1 $\beta$. More importantly, pretreatment with (+)-naloxone (an inhibitor of TLR4), A438079 (an inhibitor of P2 $\times 7 R$ ), and ac-YVAD-cmk (an inhibitor of caspase-1) could attenuate the development of remifentanil-induced mechanical and thermal hyperalgesia during the postoperative period, which might be via regulation of IL-1 $\beta$, Phospho-NR1 and GLT-1. In conclusion, these results demonstrate that NLRP3 inflammasome activation contributes to RIH via regulation of Phospho-NR1 and GLT-1. IL-1 $\beta$ mediated this process.

In clinical practice, patients always accept anesthesia and operation simultaneously. So Incision + Remifentanil group was designed to imitate RIH in clinical practice. We used a rat model of postoperative pain that was first described by Brennan [21]. Sevoflurane was selected for anaesthesia because it has been proved to be uninfluential on nociceptive thresholds[22]. In the present study, we adopted $1.2 \mu \mathrm{g}$. $\mathrm{kg}^{-1} \cdot \mathrm{min}^{-1}$ as the rate of remifentanil infusion according to clinical practice. The dosage has been proved to induce hyperalgesia by behavioral tests[22]. It is known that RIH in rats arises $2 \mathrm{~h}$ after remifentanil infusion and reaches the maximum 24-48 $\mathrm{h}$ after remifentanil infusion[24]. RIH lasts at least 7 days after remifentanil infusion[25]. Therefore, we chose $24 \mathrm{~h}$ before surgery and $2 \mathrm{~h}, 6 \mathrm{~h}, 24 \mathrm{~h}$, and $48 \mathrm{~h}$ after remifentanil infusion as the time points for behavioral tests . 


\section{IL-1 $\beta$ contributes to RIH via regulation of Phospho-NR1 and GLT-1}

Recent studies suggest that neuroimmune signalling accompanies $\mathrm{OlH}$. Chang reported that incisions and/or fentanyl administration increased the expression of IL-1 $\beta$, IL-6 and TNF- $\alpha$ in the spinal cord[26]. Hong reported that spinal astrocyte activation and an inflammatory reaction are involved in $\mathrm{RIH}[27]$. Lv reported that attenuation of RIH by betulinic acid was associated with potential inhibition of oxidative stress and subsequent downregulation of IL-1 $\beta$ in the spinal dorsal horn[28].

Here, we show that (1) the spinal proinflammatory cytokine IL-1 $\beta$, which is a key mediator of the inflammatory cascade, was increased by an incision and further amplified by remifentanil; (2) PhosphoNR1 was elevated, whereas GLT-1 decreased by the combination of an incision and remifentanil; (3) inhibition of IL-1 $\beta$ before remifentanil administration prevented hyperalgesia; and (4) inhibition of IL-1 $\beta$ before remifentanil administration reversed the changes in Phospho-NR1 and GLT-1. These findings indicate that IL-1 $\beta$ contributes to RIH via regulation of Phospho-NR1 and GLT-1.

\section{NLRP3 inflammasome activation and RIH}

We designed the experiments to test whether spinal NLRP3 inflammasome activation caused RIH. Thus, the NLRP3 inflammasome platform was pharmacologically inhibited at several levels and followed by assessment of the behavioural and biochemical consequences of RIH. The role of spinal TLR4 was explored as the first signal for NLRP3 inflammasome activation. Intrathecal infusion of the TLR4 antagonist (+)-naloxone[29] prevented the development of RIH. Next, the role of spinal P2 $\times 7 \mathrm{R}$ was explored as the second signal for NLRP3 inflammasome activation. Intrathecal infusion of A438079[29], a selective P $2 \times 7 \mathrm{R}$ antagonist, prevented the development of RIH. The role of spinal caspase- 1 was then explored because it is the enzyme responsible for the proteolytic activation of IL-1 $\beta[8]$. Intrathecal infusion of a caspase-1 antagonist, N-Ac-Tyr-Val-Ala-Asp-chloromethyl ketone (ac-YVAD-cmk)[31], prevented the development of RIH. These findings provide evidence that RIH depends on TLR4, P2 $\times 7 R$, and caspase-1 signalling. Therefore, we can conclude that spinal NLRP3 inflammasome activation caused RIH.

\section{NLRP3 inflammasome activation contributes to RIH via regulation of IL-1 $\beta$}

Phospho-NR1 and GLT-1 are markers of IL-1 $\beta$-induced neuroexcitation. They were quantified after administration of (+)-naloxone, A438079, and ac-YVAD-cmk. All inhibitors decreased the expression of phospho-NR1 and increased the expression of GLT-1 relative to vehicle controls. These findings provide biochemical support for the attenuated IL-1 $\beta$ signalling.

In this study, we implicated the spinal NLRP3 inflammasome activation in RIH, discovering that spinal NLRP3 inflammasomes mediate the initiation of RIH because (1) TLR4, P2 $\times 7 R$, NLRP3, and caspase-1 were elevated by incisions, while remifentanil enhanced these markers and (2) inhibition of TLR4, P2 $\times 7 R$, 
or caspase- 1 before remifentanil administration prevented hyperalgesia. The mechanisms by which remifentanil activated NLRP3 inflammasomes are unknown. Our results suggested that the expression of IL-1 $\beta$ increased by an incision and further amplified by remifentanil. Then increased IL-1 $\beta$ mediated the down-regulation of GLT-1 followed by the elevated glutamate. Elevated glutamate may trigger ATP release from glia[32, 33]. ATP activated P2 $\times 7 R$, which is the second message for the activation of NLRP3 inflammasome[34, 35]. It has also been demonstrated that $\mathrm{OIH}$ induced by systemic low-dose morphine shares action at TLR4 and signalling via protein kinase $C \varepsilon[36]$. However, the possible mechanism underlying NLRP3 inflammasome activation is unclear and needs to be clarified in the future.

Our study demonstrated how NLRP3 inflammasome activation contributes to RIH. We discovered that inhibition of TLR4, P2 $\times 7 R$, or caspase- 1 before remifentanil administration reversed the elevated IL-1 $\beta$ and Phospho-NR1 and the decreased GLT-1 by incisions and remifentanil. Notably, the release of mature IL-1 $\beta$ requires cleavage from the precursor protein pro-IL-1 $\beta$. Cleavage of pro-IL-1 $\beta$ is achieved via caspase-1, which is activated following the formation and activation of the NLRP3 inflammasome. This result demonstrates that NLRP3 inflammasome inhibition can prevent RIH via regulation of the levels of IL-1 $\beta$, Phospho-NR1 and GLT-1.

In summary, NLRP3 inflammasome activation contributes to RIH via regulation of Phospho-NR1 and GLT1 by IL-1 $\beta$. Inhibition of NLRP3 inflammasome activation may be an effective and novel option for the treatment of RIH. The present work may shed a new light on the prevention and treatment of $\mathrm{OIH}$.

\section{Conclusions}

IL-1 $\beta$ contributes to RIH via regulation of Phospho-NR1 and GLT-1. Spinal NLRP3 inflammasome activation contributes to RIH. Additionally, when the NLRP3 inflammasome platform was pharmacologically inhibited at several levels of TLR4, P2 $\times 7 R$, and caspase-1, RIH was significantly reversed. Moreover, the inhibition of TLR4, P2 $\times 7 R$, or caspase- 1 before remifentanil administration reversed the elevated IL-1 $\beta$ and Phospho-NR1 and the decreased GLT-1 by incisions and remifentanil. The release of mature IL-1 $\beta$ depends on caspase- 1 , which is activated following the formation and activation of the NLRP3 inflammasome. We inferred that NLRP3 inflammasome activation contributes to RIH and is achieved by the regulation role of IL-1 $\beta$ on Phospho-NR1 and GLT-1. This conclusion can better guide clinical prevention of RIH. Inhibition of NLRP3 inflammasome activation may be an effective and novel option for the treatment of RIH. The present work may shed a new light on the prevention and treatment of RIH.

\section{List Of Abbreviations}

NOD-like receptor protein 3 (NLRP3)

remifentanil-induced postoperative hyperalgesia $(\mathrm{RIH})$

N-methyl-D-aspartate (NMDA) 
glutamate transporter-1 (GLT-1)

interleukin-1 $\beta(I L-1 \beta)$

phosphorylation of NR1 NMDA receptor subunits (Phospho-NR1)

opioid-induced hyperalgesia $(\mathrm{OIH})$

danger-associated molecular patterns (DAMPs)

Toll-like receptor 4 (TLR4)

apoptosis-associated speck-like protein containing a CARD (ASC)

paw withdrawal threshold (PWT)

paw withdrawal latency (PWL)

glyceraldehyde-3-phosphate dehydrogenase (GAPDH)

Enzyme-linked immunosorbent assay (ELISA)

N-Ac-Tyr-Val-Ala-Asp-chloromethyl ketone (ac-YVAD-cmk)

\section{Declarations}

\section{Ethics approval and consent to participate}

The experimental procedures in this study were approved by the Ethics Committee for Animal Experimentation of the Medical University of Tianjin, China (Aecl2015-0158 [JIN]).

\section{Consent for publication}

Not applicable.

\section{Availability of data and materials}

The datasets generated during the current study are available from the corresponding author on reasonable request.

\section{Competing interests}

The authors declare that they have no competing interests.

\section{Funding}


This work was supported by grants from the National Natural Science Foundation of China (grant number 81300960), Science and Technology Foundation of Tianjin Health Bureau (2013KZ124), and Tianjin Applied Basic and Frontier Technology Research Program (14JCQNJC12800). The funders played an important role in the design of the study, collection, analysis, and interpretation of the data and writing the manuscript.

\section{Authors' contributions}

$Y Y^{1}$ and $Y Y^{2}$ conceived the project plan. $Y Y[1], C W$ and $B D$ planned, performed, and analysed the experiments. $\mathrm{KX}$ and $\mathrm{BD}$ collated and analysed the data. $\mathrm{YY^{1 }}$ wrote the manuscript, and all authors discussed, modified and approved the final version. $Y Y^{2}$ initiated and supervised the project. All authors have read and approved the final manuscript.

\section{Acknowledgements}

Not applicable.

[1] Yuan Yuan

2 Yonghao Yu

\section{References}

1. Mercadante S, Arcuri E, Santoni A. Opioid-Induced Tolerance and Hyperalgesia. CNS DRUGS. 2019;33(10):943-55.

2. Yi P, Pryzbylkowski P. Opioid Induced Hyperalgesia. PAIN MED. 2015;16(Suppl 1):32-6.

3. Santonocito C, Noto A, Crimi C, Sanfilippo F. Remifentanil-induced postoperative hyperalgesia: current perspectives on mechanisms and therapeutic strategies. Local Reg Anesth. 2018;11:15-23.

4. Fletcher $D$, Martinez V. Opioid-induced hyperalgesia in patients after surgery: a systematic review and a meta-analysis. Br J Anaesth. 2014;112(6):991-1004.

5. Niedermayer S, Heyn J, Guenther F, Kuchenhoff H, Luchting B. Remifentanil for abdominal surgery is associated with unexpectedly unfavorable outcomes; 2019.

6. Dinarello CA. A clinical perspective of IL-1beta as the gatekeeper of inflammation. EUR J IMMUNOL. 2011;41(5):1203-17.

7. de Rivero VJ, Dietrich WD, Keane RW. Activation and regulation of cellular inflammasomes: gaps in our knowledge for central nervous system injury. J Cereb Blood Flow Metab. 2014;34(3):369-75.

8. Latz E, Xiao TS, Stutz A. Activation and regulation of the inflammasomes. NAT REV IMMUNOL. 2013;13(6):397-411.

9. Araldi D, Bogen O, Green PG, Levine JD. Role of Nociceptor Toll-like Receptor 4 (TLR4) in OpioidInduced Hyperalgesia and Hyperalgesic Priming. J NEUROSCI. 2019;39(33):6414-24. 
10. Franceschini A, Capece M, Chiozzi P, Falzoni S, Sanz JM, Sarti AC, Bonora M, Pinton P, Di Virgilio F. The P2 $\times 7$ receptor directly interacts with the NLRP3 inflammasome scaffold protein. FASEB J. 2015;29(6):2450-61.

11. Zhang RX, Li A, Liu B, Wang L, Ren K, Zhang H, Berman BM, Lao L. IL-1ra alleviates inflammatory hyperalgesia through preventing phosphorylation of NMDA receptor NR-1 subunit in rats. PAIN. 2008;135(3):232-9.

12. Yan X, Yadav R, Gao M, Weng HR: Interleukin-1 beta enhances endocytosis of glial glutamate transporters in the spinal dorsal horn through activating protein kinase C. GLIA 2014, 62(7):10931109.

13. Yuan Y, Wang JY, Yuan F, Xie KL, Yu YH, Wang GL. Glycogen synthase kinase-3beta contributes to remifentanil-induced postoperative hyperalgesia via regulating $\mathrm{N}$-methyl-D-aspartate receptor trafficking. ANESTH ANALG. 2013;116(2):473-81.

14. Vasefi MS, Yang K, Li J, Kruk JS, Heikkila JJ, Jackson MF, MacDonald JF, Beazely MA. Acute 5-HT7 receptor activation increases NMDA-evoked currents and differentially alters NMDA receptor subunit phosphorylation and trafficking in hippocampal neurons. MOL BRAIN. 2013;6:24.

15. Pajarillo E, Rizor A, Lee J, Aschner M, Lee E. The role of astrocytic glutamate transporters GLT-1 and GLAST in neurological disorders: Potential targets for neurotherapeutics. NEUROPHARMACOLOGY. 2019;161:107559.

16. Cui W, Li Y, Li S, Yang W, Jiang J, Han S, Li J. Systemic lidocaine inhibits remifentanil-induced hyperalgesia via the inhibition of cPKCgamma membrane translocation in spinal dorsal horn of rats. J Neurosurg Anesthesiol. 2009;21(4):318-25.

17. Grace PM, Strand KA, Galer EL, Urban DJ, Wang X, Baratta MV, Fabisiak TJ, Anderson ND, Cheng K, Greene LI, et al. Morphine paradoxically prolongs neuropathic pain in rats by amplifying spinal NLRP3 inflammasome activation. Proc Natl Acad Sci U S A. 2016;113(24):E3441-50.

18. Milligan ED, Hinde JL, Mehmert KK, Maier SF, Watkins LR. A method for increasing the viability of the external portion of lumbar catheters placed in the spinal subarachnoid space of rats. J Neurosci Methods. 1999;90(1):81-6.

19. Brennan TJ, Vandermeulen EP, Gebhart GF. Characterization of a rat model of incisional pain. PAIN. 1996;64(3):493-501.

20. Schmittgen TD, Livak KJ. Analyzing real-time PCR data by the comparative C(T) method. NAT PROTOC. 2008;3(6):1101-8.

21. Brennan TJ, Zahn PK, Pogatzki-Zahn EM. Mechanisms of incisional pain. Anesthesiol Clin North Am. 2005;23(1):1-20.

22. Celerier E, Gonzalez JR, Maldonado R, Cabanero D, Puig MM. Opioid-induced hyperalgesia in a murine model of postoperative pain: role of nitric oxide generated from the inducible nitric oxide synthase. ANESTHESIOLOGY. 2006;104(3):546-55.

23. Cui W, Li Y, Li S, Yang W, Jiang J, Han S, Li J. Systemic lidocaine inhibits remifentanil-induced hyperalgesia via the inhibition of cPKCgamma membrane translocation in spinal dorsal horn of rats. 
J Neurosurg Anesthesiol. 2009;21(4):318-25.

24. Gu X, Wu X, Liu Y, Cui S, Ma Z. Tyrosine phosphorylation of the N-Methyl-D-Aspartate receptor 2B subunit in spinal cord contributes to remifentanil-induced postoperative hyperalgesia: the preventive effect of ketamine. MOL PAIN. 2009;5:76.

25. Cabanero D, Campillo A, Celerier E, Romero A, Puig MM. Pronociceptive effects of remifentanil in a mouse model of postsurgical pain: effect of a second surgery. ANESTHESIOLOGY. 2009;111(6):1334-45.

26. Chang L, Ye F, Luo Q, Tao Y, Shu H. Increased Hyperalgesia and Proinflammatory Cytokines in the Spinal Cord and Dorsal Root Ganglion After Surgery and/or Fentanyl Administration in Rats. ANESTH ANALG. 2018;126(1):289-97.

27. Hong HK, Ma Y, Xie H. TRPV1 and spinal astrocyte activation contribute to remifentanil-induced hyperalgesia in rats. NEUROREPORT. 2019;30(16):1095-101.

28. Lv CC, Xia ML, Shu SJ, Chen F, Jiang LS: Attenuation of Remifentanil-Induced Hyperalgesia by Betulinic Acid Associates with Inhibiting Oxidative Stress and Inflammation in Spinal Dorsal Horn. PHARMACOLOGY 2018, 102(5-6):300-306.

29. Hutchinson MR, Zhang Y, Brown K, Coats BD, Shridhar M, Sholar PW, Patel SJ, Crysdale NY, Harrison JA, Maier SF, et al. Non-stereoselective reversal of neuropathic pain by naloxone and naltrexone: involvement of toll-like receptor 4 (TLR4). EUR J NEUROSCI. 2008;28(1):20-9.

30. Nelson DW, Gregg RJ, Kort ME, Perez-Medrano A, Voight EA, Wang Y, Grayson G, Namovic MT, Donnelly-Roberts DL, Niforatos W, et al. Structure-activity relationship studies on a series of novel, substituted 1-benzyl-5-phenyltetrazole P2 × 7 antagonists. J MED CHEM. 2006;49(12):3659-66.

31. Rabuffetti M, Sciorati C, Tarozzo G, Clementi E, Manfredi AA, Beltramo M. Inhibition of caspase-1-like activity by Ac-Tyr-Val-Ala-Asp-chloromethyl ketone induces long-lasting neuroprotection in cerebral ischemia through apoptosis reduction and decrease of proinflammatory cytokines. J NEUROSCl. 2000;20(12):4398-404.

32. Liu GJ, Kalous A, Werry EL, Bennett MR. Purine release from spinal cord microglia after elevation of calcium by glutamate. MOL PHARMACOL. 2006;70(3):851-9.

33. Queiroz G, Meyer DK, Meyer A, Starke K, von Kugelgen I. A study of the mechanism of the release of ATP from rat cortical astroglial cells evoked by activation of glutamate receptors. NEUROSCIENCE. 1999;91(3):1171-81.

34. Ficker C, Rozmer K, Kato E, Ando RD, Schumann L, Krugel U, Franke H, Sperlagh B, Riedel T, Illes P. Astrocyte-neuron interaction in the substantia gelatinosa of the spinal cord dorsal horn via P2 $\times 7$ receptor-mediated release of glutamate and reactive oxygen species. GLIA. 2014;62(10):1671-86.

35. Suadicani SO, Brosnan CF, Scemes E: $P 2 \times 7$ receptors mediate ATP release and amplification of astrocytic intercellular Ca2 + signaling. J NEUROSCI 2006, 26(5):1378-1385.

36. Araldi D, Bogen O, Green PG, Levine JD. Role of Nociceptor Toll-like Receptor 4 (TLR4) in OpioidInduced Hyperalgesia and Hyperalgesic Priming. J NEUROSCI. 2019;39(33):6414-24. 


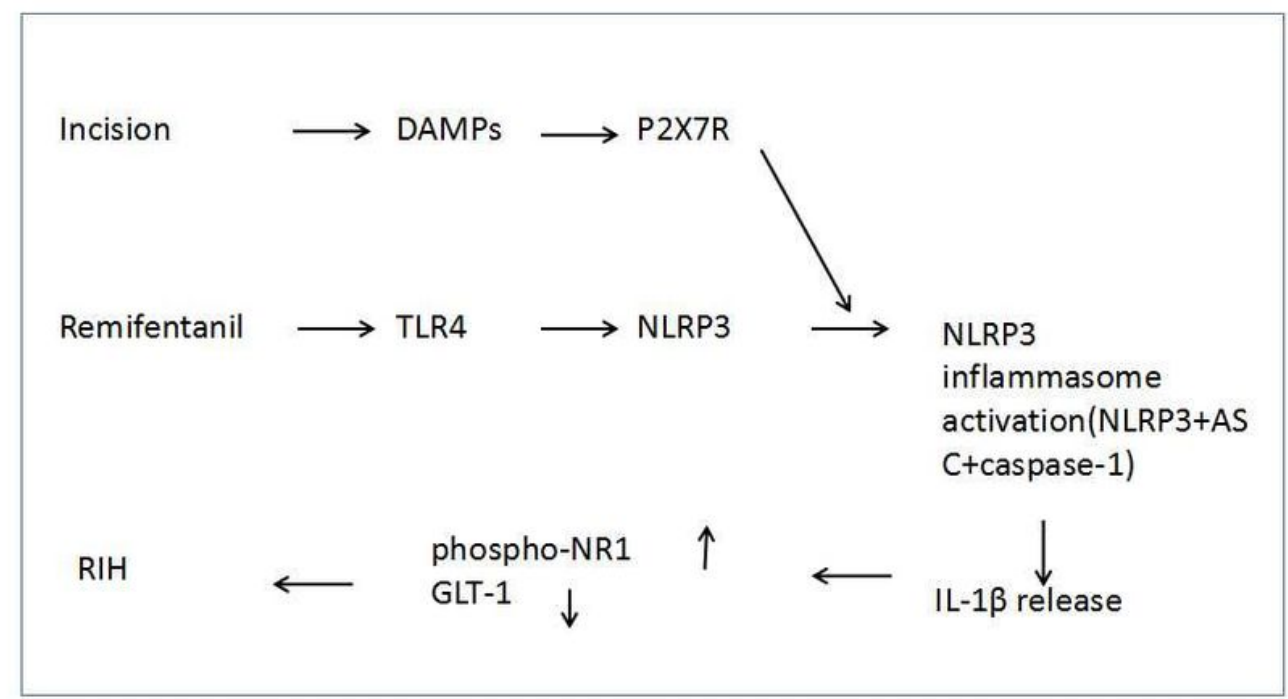

Figure 1

The design concept of our study.

A

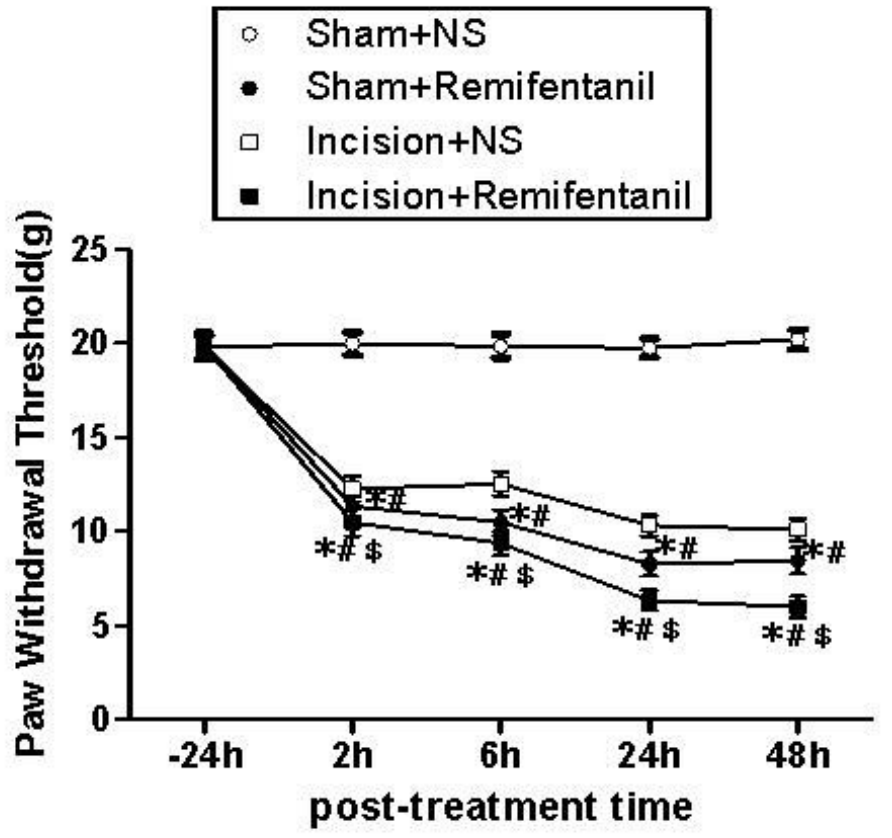

B

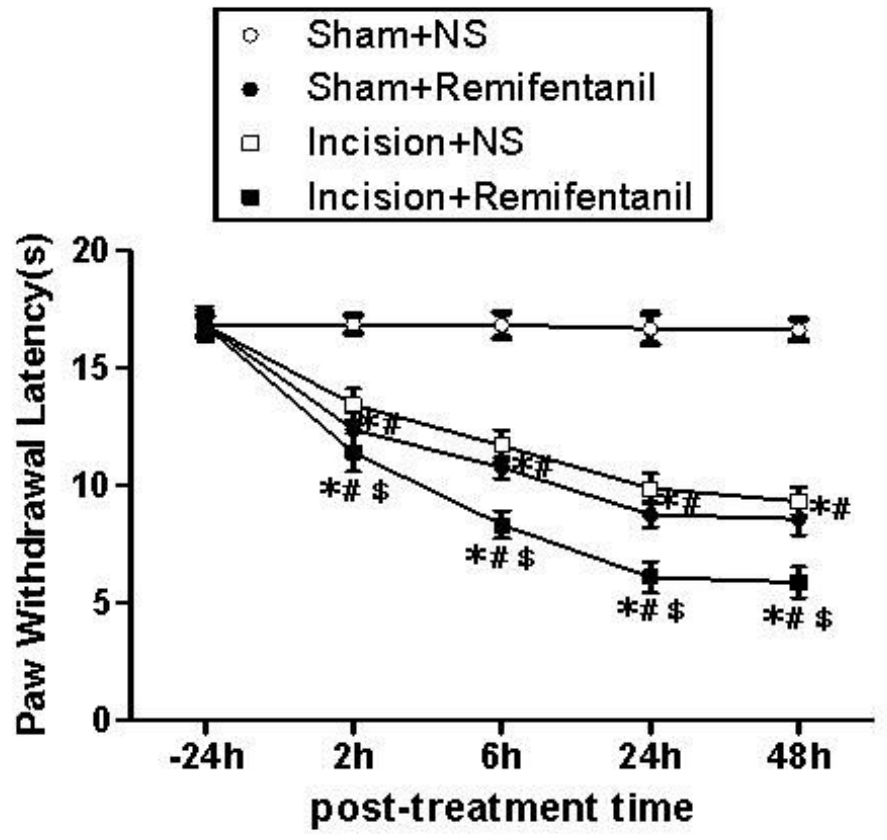


Figure 2

Assessment of the effects of remifentanil on postoperative hyperalgesia. Under sevoflurane anaesthesia, remifentanil (1.2 $\mu \mathrm{g} \cdot \mathrm{kg}-1 \cdot \mathrm{min}-1)$ or saline was intravenously infused in the absence or presence of a left hind paw incision for 60 min. The PWT to von Frey filament stimulation (A) and PWL to thermal stimulation (B) were evaluated $24 \mathrm{~h}$ before the incision and $2 \mathrm{~h}, 6 \mathrm{~h}, 24 \mathrm{~h}$, and $48 \mathrm{~h}$ after remifentanil infusion. The data are presented as the mean $\pm S D$. $n=8$ per group. ${ }^{*}<<0.01$ compared to baseline, $\# \mathrm{P}<0.01$ compared to the Sham+NS group (control), $\otimes \mathrm{P}<0.01$ compared to the Incision+NS group.

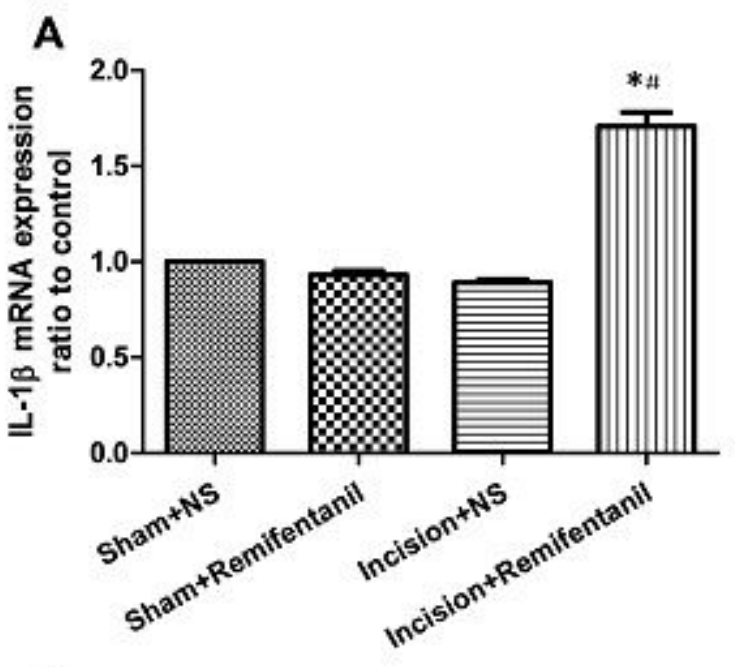

C
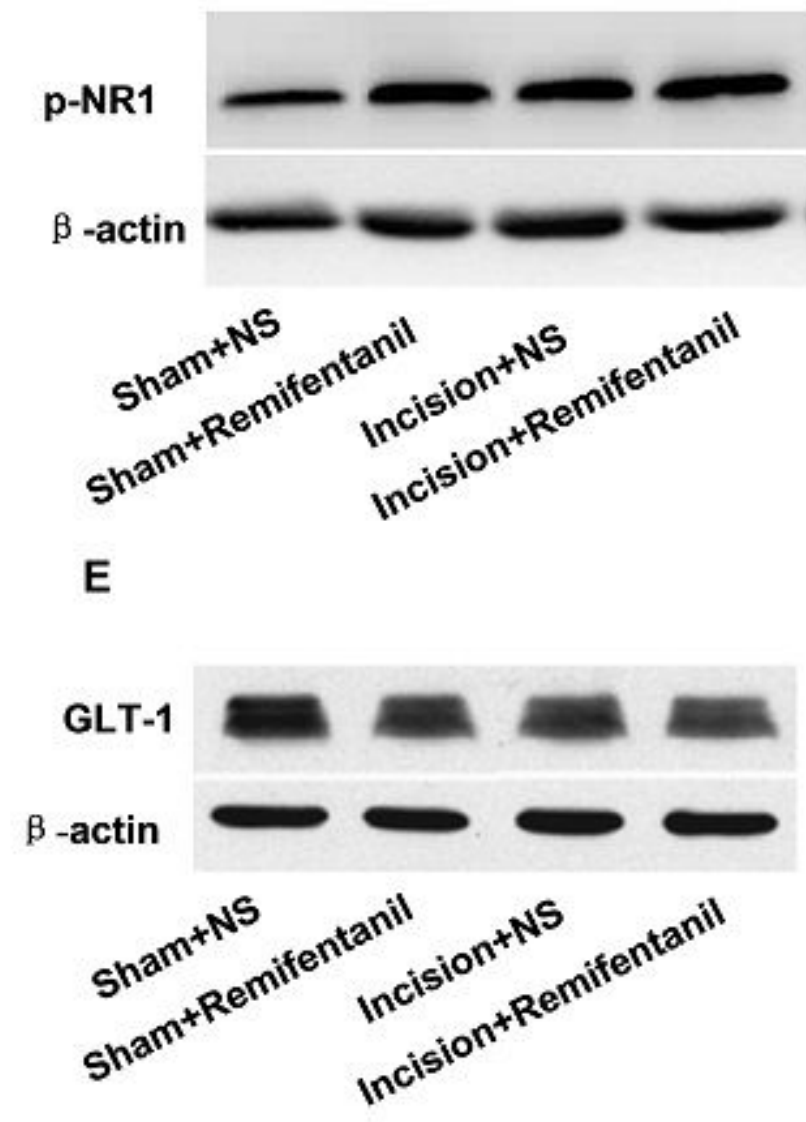

B

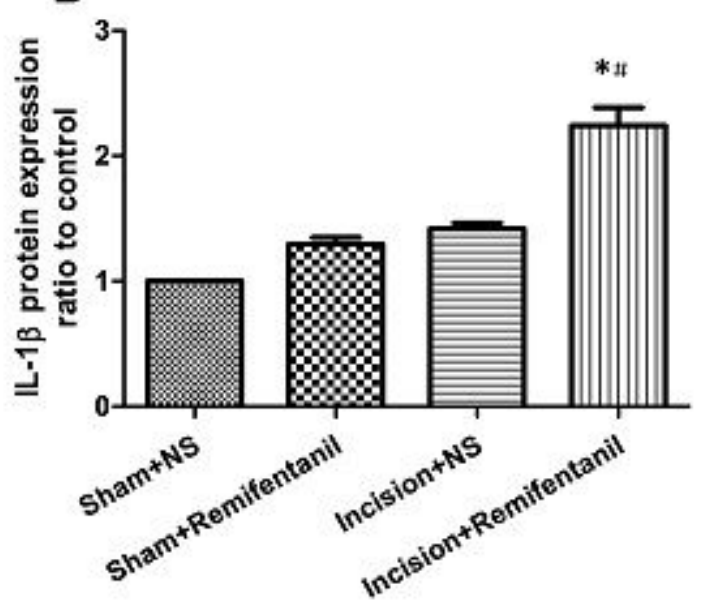

D

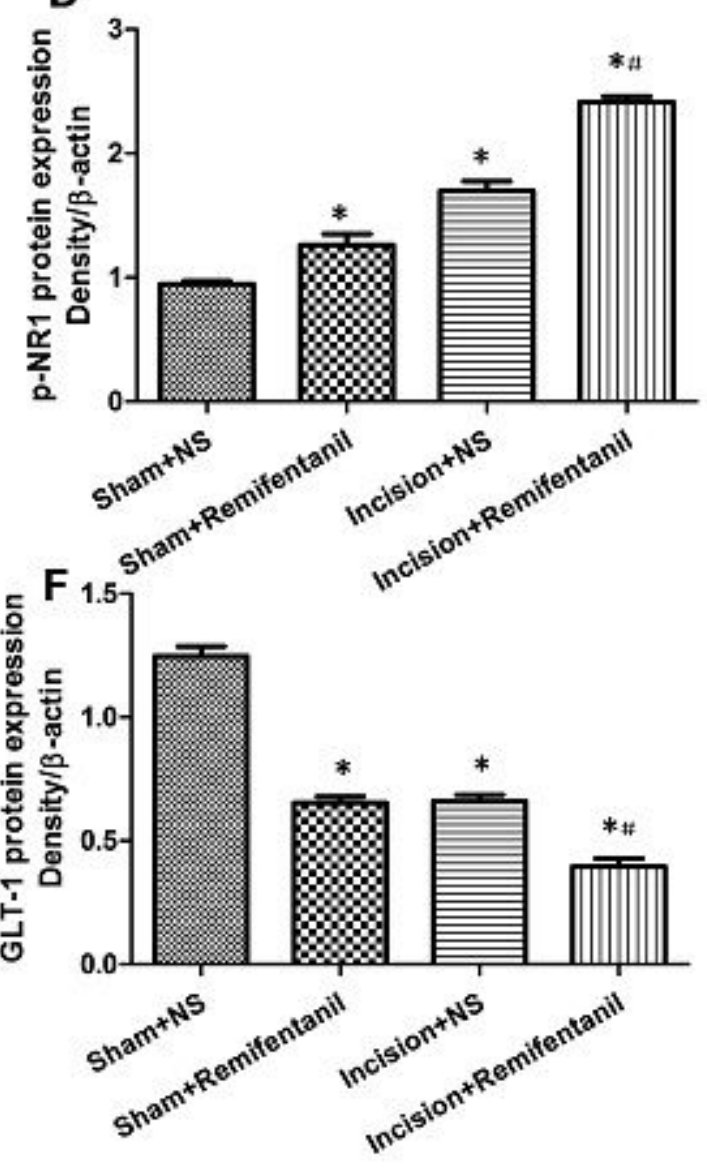

Figure 3 
Assessment of the effects of remifentanil on IL-1 $\beta$ mRNA and protein, Phospho-NR1 and GLT-1 protein in the L4-L6 spinal cord of rats. Incisions significantly increased IL-1 $\beta$ mRNA (A), IL-1 $\beta$ protein (B), and Phospho-NR1 ( $C$ and D) and decreased GLT-1 protein ( $E$ and F), which were further amplified by remifentanil. The data are presented as the mean \pm SD. $n=8$ per group. ${ }^{*} P<0.01$ compared to the Sham+NS group (control), \#P<0.01 compared to the Incision+NS group.

A

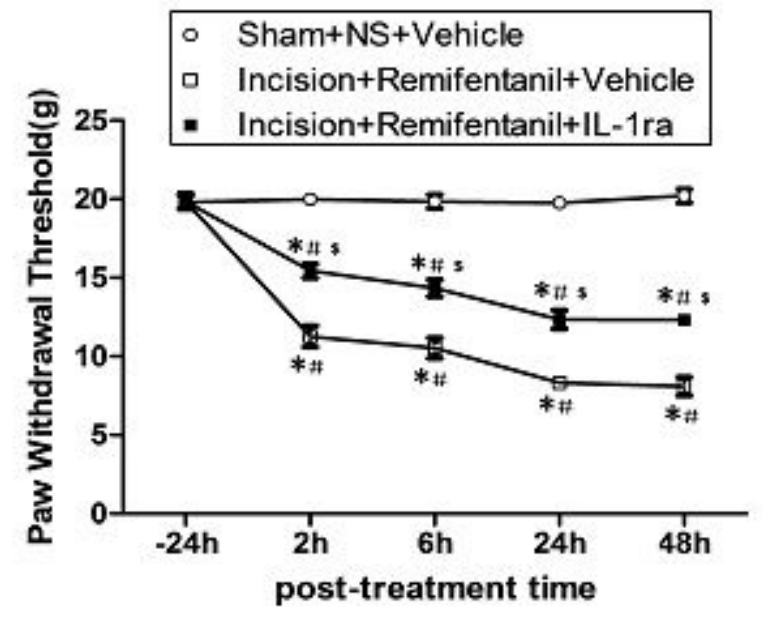

B

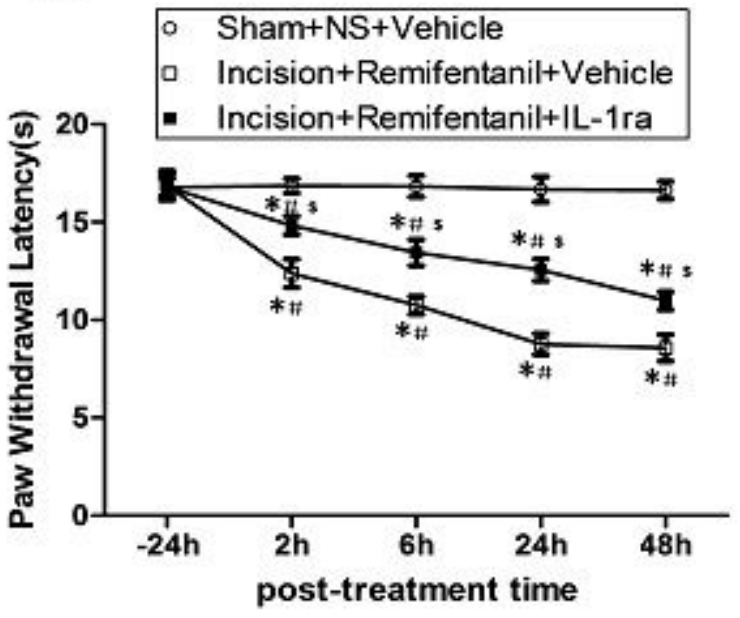

Figure 4

Assessment of the effects of IL-1ra, an IL-1 $\beta$ inhibitor, on RIH. Under sevoflurane anaesthesia, remifentanil (1.2 $\mu \mathrm{g} \cdot \mathrm{kg}-1 \cdot \mathrm{min}-1)$ or saline was intravenously infused in the absence or presence of a left hind paw incision for $60 \mathrm{~min}$. IL-1ra $(100 \mu \mathrm{g} / 10 \mu \mathrm{L})$ or equivolume saline was intrathecally infused immediately before remifentanil or saline infusion. The PWT to von Frey filament stimulation $(A)$ and PWL to thermal stimulation (B) were evaluated $24 \mathrm{~h}$ before the incision and $2 \mathrm{~h}, 6 \mathrm{~h}, 24 \mathrm{~h}$, and $48 \mathrm{~h}$ after remifentanil infusion. The data are presented as the mean \pm SD. $n=8$ per group. ${ }^{*} P<0.01$ compared to

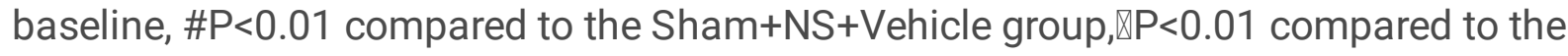
Incision+Remifentanil+vehicle group. 
A

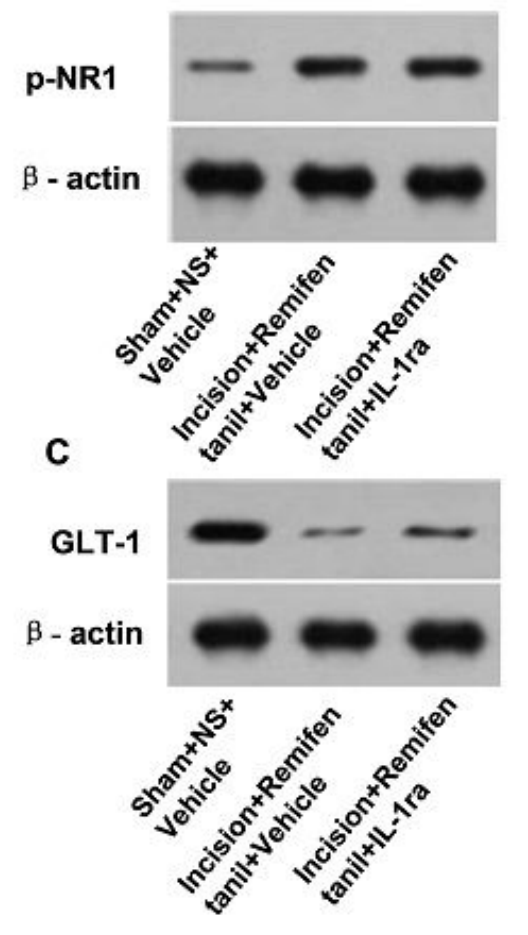

B

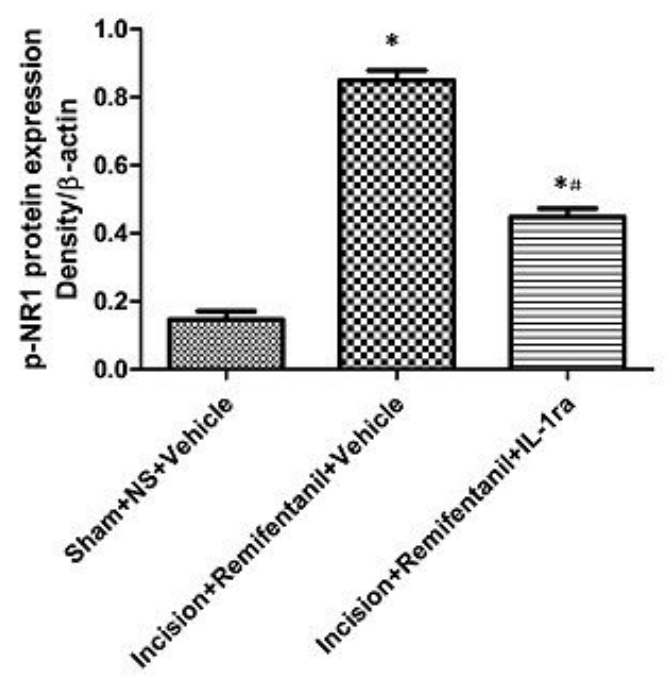

D

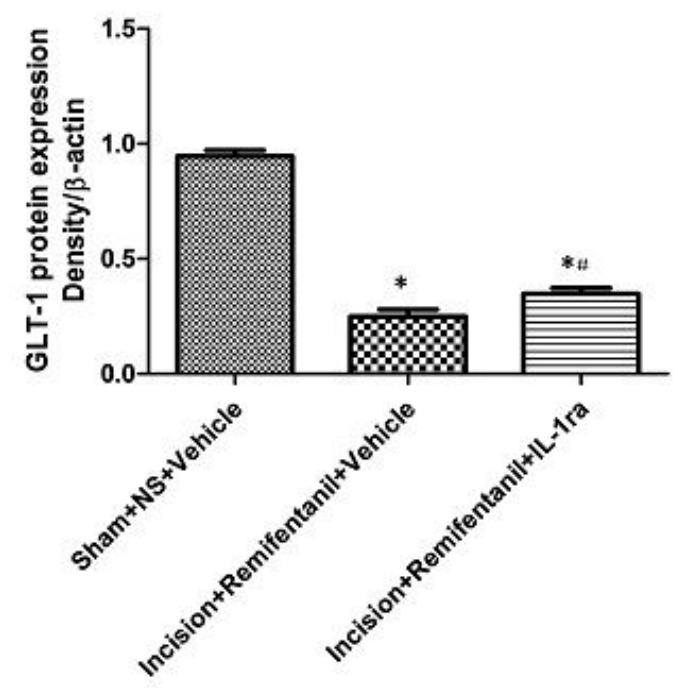

\section{Figure 5}

Assessment of the effects of IL-1ra, an IL-1 $\beta$ inhibitor, on Phospho-NR1 and GLT-1 protein in the L4-L6 spinal cord of rats. IL-1ra (100 $\mu \mathrm{g} / 10 \mu \mathrm{L}$ intrathecal) reversed the amplified increased Phospho-NR1 (A and $B$ ) and decreased GLT-1 protein ( $C$ and $D)$ by remifentanil. The data are presented as the mean \pm SD. $\mathrm{n}=8$ per group. ${ }^{*} \mathrm{P}<0.01$ compared to the Sham+NS+vehicle group (control), $\# \mathrm{P}<0.01$ compared to the Incision+Remifentanil+vehicle group.

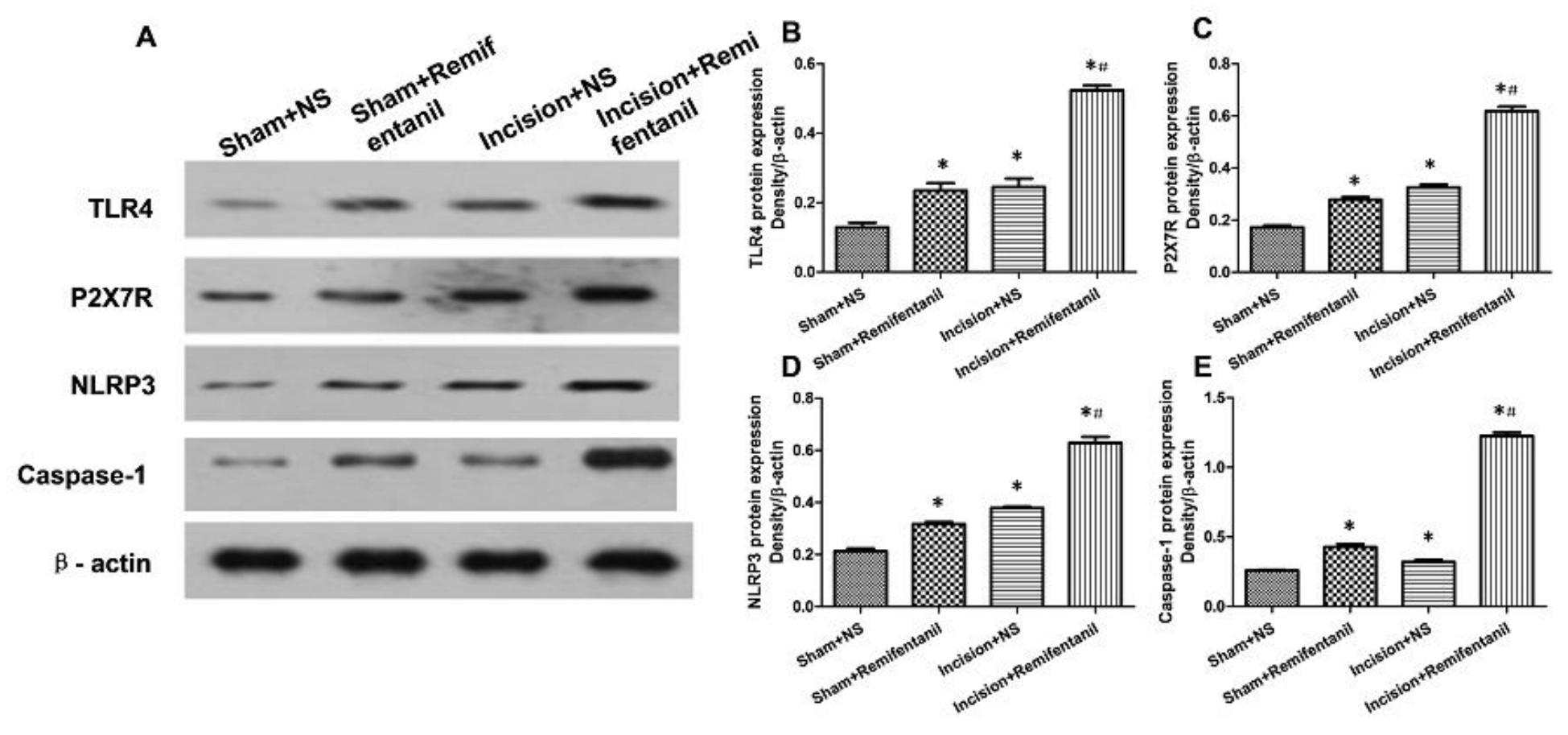

Figure 6 
Assessment of the effects of remifentanil on TLR4, P2X7R, NLRP3, and caspase-1 protein in the L4-L6 spinal cord of rats. Incisions significantly increased TLR4 (B), P2X7R (C), NLRP3 (D), and caspase-1 (E) protein, which were further amplified by remifentanil. The data are presented as the mean $\pm S D$. $n=8$ per group. ${ }^{*} \mathrm{P}<0.01$ compared to the Sham+NS group (control), $\# \mathrm{P}<0.01$ compared to the Incision+NS group.
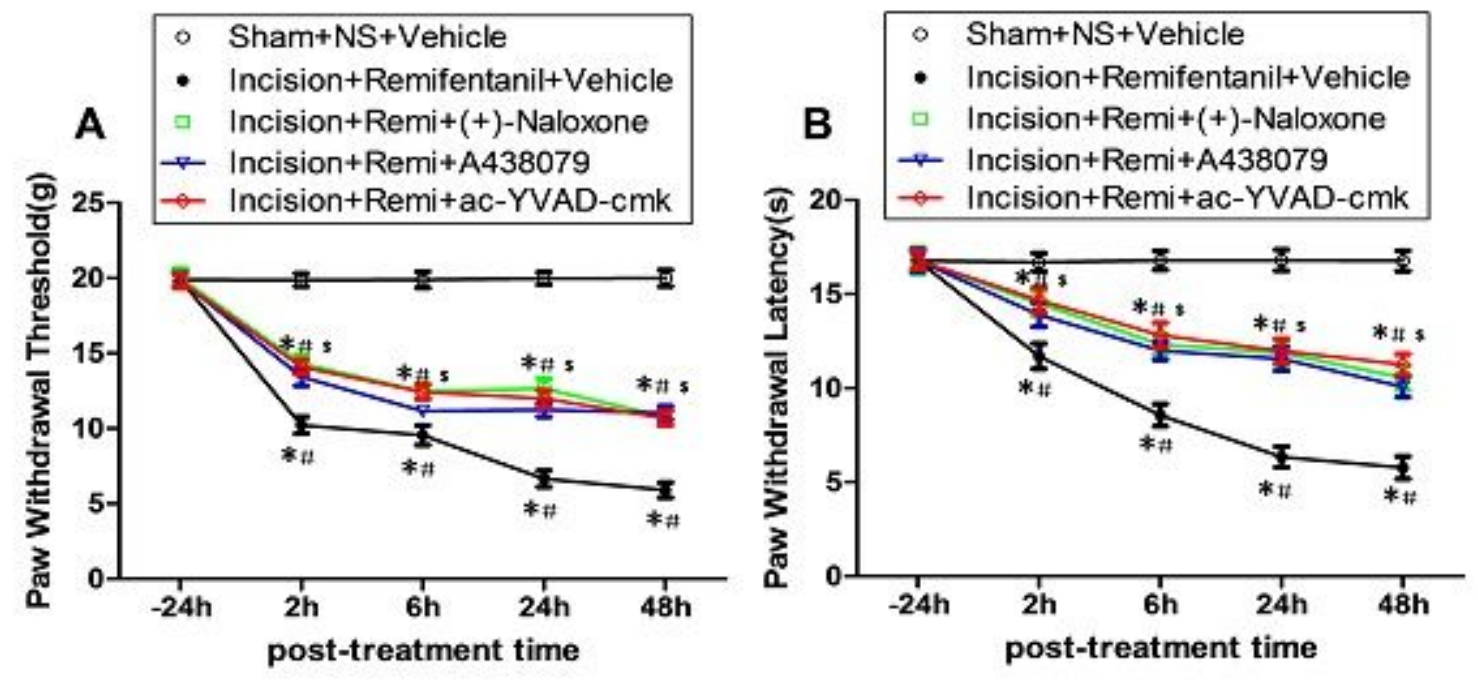

\section{Figure 7}

Assessment of the effects of NLRP3 inflammasome inhibition on RIH. (+)-Naloxone (1200 $\mu \mathrm{g} / 10 \mu \mathrm{L})$, A438079 $(600 \mathrm{ng} / 10 \mu \mathrm{L})$, ac-YVAD-cmk $(20 \mu \mathrm{g} / 10 \mu \mathrm{L})$, or equivolume vehicles were intrathecally infused immediately before remifentanil or saline infusion. The PWT to von Frey filament stimulation $(A)$ and PWL to thermal stimulation (B) were evaluated $24 \mathrm{~h}$ before the incision and $2 \mathrm{~h}, 6 \mathrm{~h}, 24 \mathrm{~h}$, and $48 \mathrm{~h}$ after remifentanil infusion. The data are presented as the mean \pm SD. $n=8$ per group. ${ }^{*} P<0.01$ compared to baseline, $\# \mathrm{P}<0.01$ compared to the Sham $+\mathrm{NS}+\mathrm{vehicle}$ group, $\triangle \mathrm{P}<0.01$ compared to the Incision+Remifentanil+vehicle group. 
A B
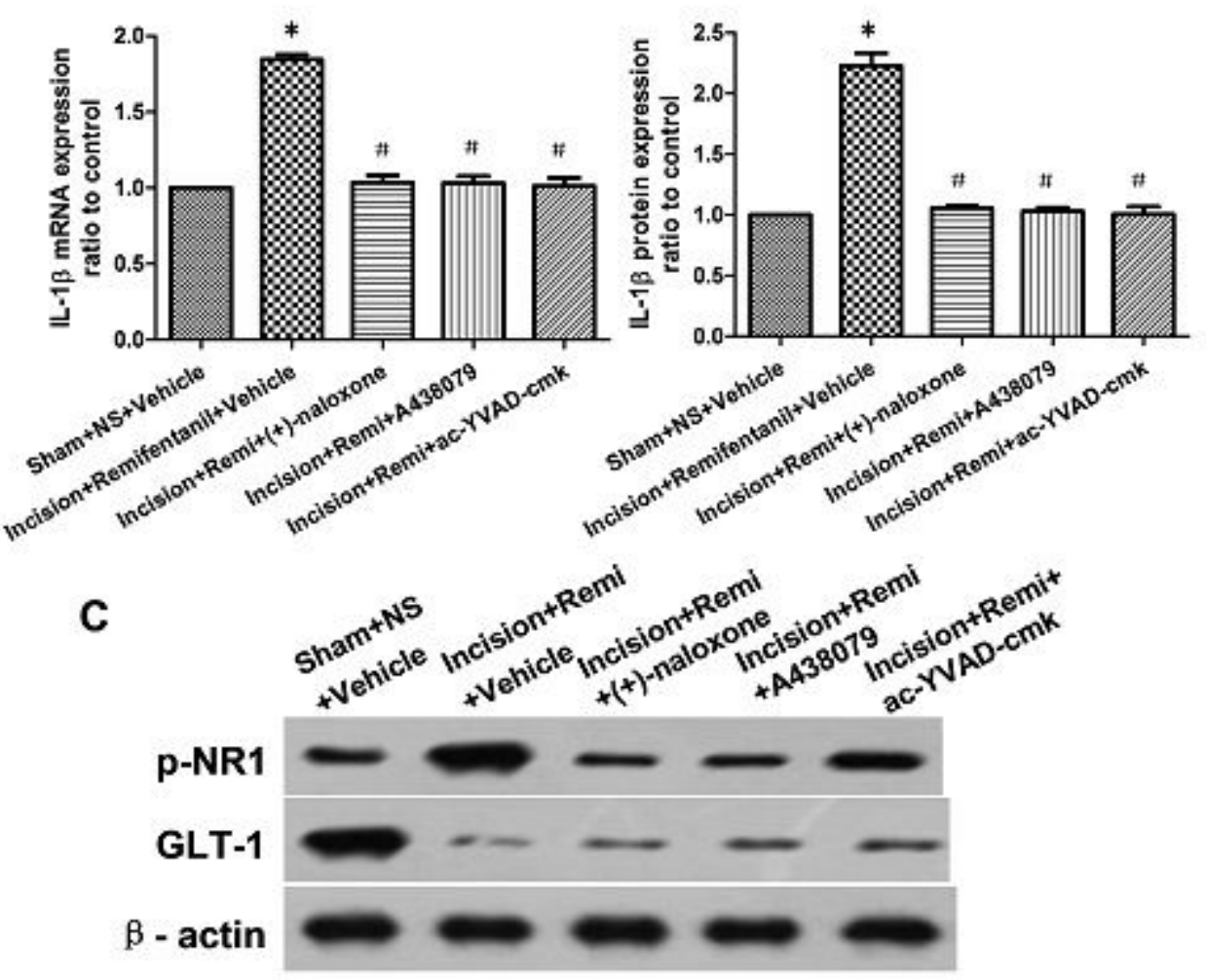

D E

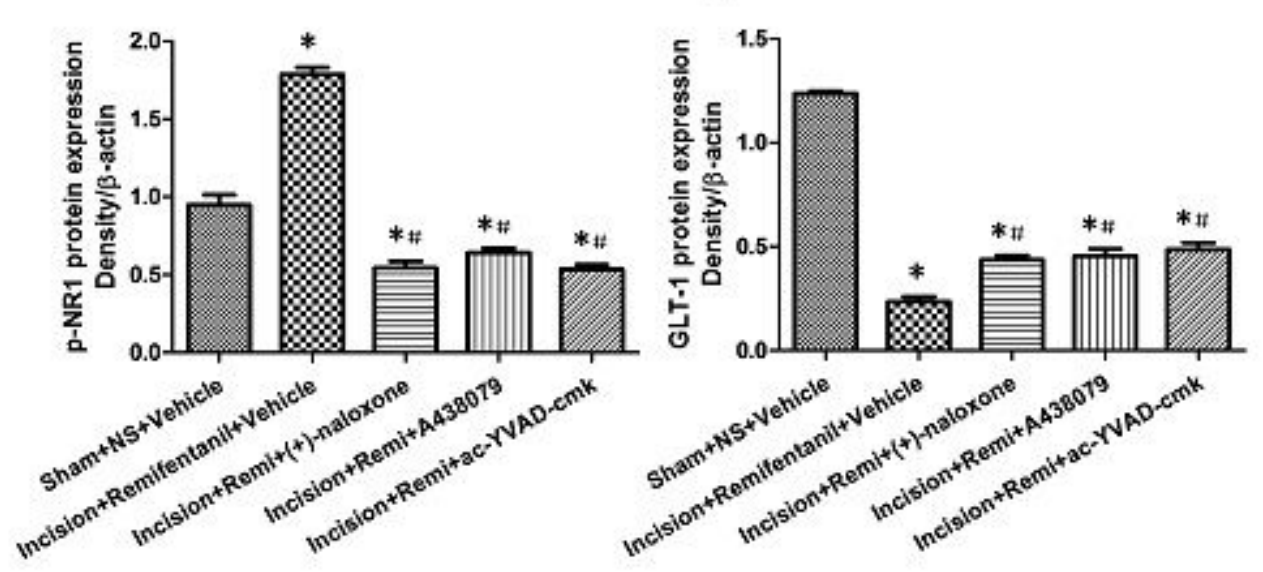

Figure 8

Assessment of the effects of NLRP3 inflammasome inhibition on IL-1 $\beta$ mRNA and protein, Phospho-NR1 and GLT-1 protein in the L4-L6 spinal cord of rats. (+)-Naloxone $(1200 \mu \mathrm{g} / 10 \mu \mathrm{L}), \mathrm{A} 438079(600 \mathrm{ng} / 10$ $\mu \mathrm{L})$, and ac-YVAD-cmk $(20 \mu \mathrm{g} / 10 \mu \mathrm{L})$ reversed the amplified increased IL-1 $\beta$ mRNA (A) and protein (B), and Phospho-NR1 ( $C$ and $D$ ) and decreased GLT-1 protein ( $C$ and $E$ ) by remifentanil. The data are presented as the mean $\pm S D$. $n=8$ per group. ${ }^{*} P<0.01$ compared to the Sham+NS+vehicle group (control), $\# \mathrm{P}<0.01$ compared to the Incision+Remifentanil+vehicle group.

\section{Supplementary Files}


This is a list of supplementary files associated with this preprint. Click to download.

- NC3RsARRIVEGuidelinesChecklist2014.docx 